\title{
Biogas Production of Ozone and/or Microwave-Pretreated Canned Maize Production Sludge
}

\author{
Sándor Beszédes, Szabolcs Kertész, Zsuzsanna László, Gábor Szabó, and Cecilia Hodúr \\ Department of Technical and Process Engineering, Faculty of Engineering, University of Szeged, Szeged, Hungary
}

\begin{abstract}
The production of canned maize is accompanied by formation of large volumes of waste water, with high contents of starch, and high chemical- and biochemical oxygen demand. In our work the effects of acidic, microwave and ozone pretreatment on the biogas production and aerobic biodegradability of canned maize production sludge were examined and the energy balance of the processes were determined when different sludge pretreatments were used. It was found that ozone treatment decreased the chemical oxygen demand, while the biochemical oxygen demand and the aerobic biodegradability increased. The combination of microwave and ozone treatment increased the biodegradability relative to ozone treatment alone.
\end{abstract}

Keywords Ozone, Sludge, Microwave, Biogas Production, Biodegradability

\section{INTRODUCTION}

Most branches of the food industry, for instance the dairy industry, the meat industry and the cannery industry have a considerable wastewater output. The problem of pollution is not caused only by the total amount of wastewater production, but also by the high content of organic matter. The development and the widespread use of waste water technologies cause a large increase in the municipal and industrial sewage sludge production. The sewage sludge is the residue of the primary, secondary or tertiary wastewater technologies. The organic matter content of the sludge is also considerable. Depending on the raw material processed, the sludge may be rich in carbohydrates, lipids or proteins. The production of canned maize also produces a high volume of waste water, with high chemical (COD) and

Received 3/6/2008; Accepted 11/25/2008

Address correspondence to Zsuzsanna László, Faculty of Engineering, University of Szeged, H-6725 Szeged, Hungary. E-mail: zsizsu@sol.cc.u-szeged.hu biochemical oxygen demands (BOD). After mechanical wastewater treatment, the COD of the sludge may be more than $100 \mathrm{~kg} \mathrm{~m}^{-3}$, because of the high content of the corn starch.

The aim of sewage sludge treatment technologies is to reduce the sludge mass or to modify it so as to make it suitable for further utilization. The methods commonly applied for sludge treatment today include digestion, dewatering, incineration or use in agriculture. But, for example, in the case of agricultural use, the existing landfill sites are running out of space and secondary pollution is becoming a serious problem. For these reasons it is most urgent to improve processes to minimize final sludge quantity. The food industrial sludge, because of its high organic content, is a special type of biomass; thus it may be utilized in biogas production. Anaerobic digestion is an appropriate technique for the treatment of sludge before its final disposal and it is used worldwide as the oldest and most important process for sludge stabilization.

The anaerobic digestion of sewage sludge has many advantages, for example the produced biogas can be used as renewable energy source: digestion has low energy requirement (if the produced biogas is used for heating of reactor); the pathogenic microorganisms are efficiently killed and digested sludge is harmless to dispose. The mesophilic anaerobic digestion of sludge has lower energy demand than thermophilic digestion. On the other hand, thermophilic anaerobic digestion provides sludge disinfection and an increased extent of methane production, and accordingly is advantageous in municipal sewage sludge treatments (Watanabe et al., 1997).

Biogas-producing fermentation involves four major steps: hydrolysis, acidogenesis, acetogenesis and methanogenesis. The rate limiting step of sludge degradation is hydrolysis, during which both solubilization of particulate matter and biological degradation of organic components can occur. Thermal, chemical, biological and mechanical processes and their different combinations have been 
studied as possible modes of pretreatment accelerating sludge hydrolysis (Gavala et al., 2003; Kim et al., 2003). These pretreatments cause the lysis or degradation of sludge cells, the organic matter therefore becoming more accessible to anaerobic microorganisms. It causes increased methane production and decreases the digestion time. The efficiency of pretreatment is commonly evaluated in terms of biodegradability or biogas production.

Ozonation is regarded as a promising preoxidation process via which to control the levels of organic pollutants in water, because ozone is a strong oxidant and a potent disinfecting agent. Compounds consisting of large molecules may decompose to smaller molecules. As a consequence of ozone treatment, organic matter may become more accessible to microorganisms (Hyung et al., 2000). Because of oxidizing of organic material, ozonation decreases the COD and volatile suspended solids (VSS) of sludge. Hereby may improve the rate of the overall digestion process and the degree of sludge degradation, there by reducing the anaerobic digester retention time, increasing methane production rates and reducing the initial lag phase of digestion (Weemates et al., 2000).

Ozonation is one of the most efficient non-thermal processes to solubilize biological sludge because ozone reacts directly and selectively with unsaturated bonds and generates radicals that oxidize organic matter. In the most cases of biological originated sludge, an ozonation process is suitable for increasing the solubilisation (Déléris et al., 2000). However in the case of activated municipal sludge a linear relation was observed between solids solubilisation and amount of consumed ozone in the range of 0 to $0.18 \mathrm{~g} \mathrm{O}_{3} / \mathrm{g}$ TS. Because of more soluble, and thereupon more easily available organic substances the biogas production enhanced, but the higher ozone doses (over $0.15 \mathrm{~g} \mathrm{O}_{3} / \mathrm{gTS}$ ) caused a decrease in biogas yield (Bougrier et al., 2007).

The use of microwaves is an alternative treatment procedure for sludge disintegration. This method is very promising because of the rapid internal heating and selective heating effects: the cell walls of both dead and living microorganisms in sludge are destroyed and the organic substances are digested due to the heat effect. The dissolved organic compounds evolved from cell fluid improve the efficiency of the biological degradation processes. During intensive microwave heating odorous compounds such as volatile fatty acids present in sludge may be reduced (Neyens and Baeyens, 2003). In the case of waste-activated sludge the main structure of sludge consists of extracellular polymeric substance (polysaccharide, proteins), other organic and inorganic matter and microbial cells that agglomerated together. This complex flock structure of sludge is resistance to a direct anaerobic degradation since cell walls and polymeric conformation present physical and chemical barriers for microbial and enzymatic degradation (Neyens et al., 2004).
Although the quantum energy of microwave radiation is too low $\left(1.05 \times 10^{-5} \mathrm{eV}\right)$ to break the chemical bounds but some structures can be altered by the energies carried by microwaves. For example the thermal effect of microwave radiation is caused by polarized parts of macromolecules, it results in breakage of hydrogen bound (Eskicioglu et al., 2007). The intensive microwave heat generation and the different dielectric properties of compounds of the cell wall lead to a rapid disruption of extracellular polymer network and residue cells of sludge. However the cell liquor and extracellular organic matter within the polymeric network can release into the soluble phase, hereby increasing the ratio of accessible and biodegradable component (Eskicioglu et al., 2006).

The aim of our present work was to examine the effects of acidic, microwave and ozone pretreatment on the biogas production and aerobic biodegradability of canned maize production sludge. Because of the high energy demands of the processes their energy balances were also examined.

\section{MATERIALS AND METHODS}

The non-pre-treated maize canning sludge originated from the DEKO Food Cannery, (Debrecen, Hungary). The chemical oxygen demand (COD) was measured before and after the treatments, by the dichromate standard method, in COD tests with an ET 108 digester and a PC CheckIt photometer (Lovibond, Germany). The initial chemical oxygen demand of the sludge was $136 \mathrm{~kg} \mathrm{~m}^{-3}$. The biochemical oxygen demand (BOD) measurements were carried out in a respirometric BOD meter (BOD Oxydirect, Lovibond, Germany), at $20{ }^{\circ} \mathrm{C}$. To ensure the consistency of the results, standard BOD aerobic microbe capsules (Cole Parmer, USA) were used in the measurements. The aerobic biodegradability during 5 days $\left(\mathrm{BD}_{5} \%\right)$ was calculated via Equation [1]

$$
\mathrm{BD}_{5} \%=\left(\mathrm{BOD}_{5} / \mathrm{COD}\right) \times 100
$$

where $\mathrm{BOD}_{5}$ is the biochemical oxygen demand (oxygen consumption) during 5 days.

The ozone treatment was performed in continuously mixed solutions diluted to $6 \%$ dry matter content. Ozone was generated from oxygen (Linde 3.0) by a flow-type ozone generator (Ozomatic Modular 4, Wedeco Ltd., Germany) operating via a silent electric discharge, and the ozone-containing gas (flow rate $1.0 \mathrm{dm}^{3} \mathrm{~min}^{-1}$ ) was bubbled through $180 \mathrm{~cm}^{3}$ of solution in a batch reactor through a ceramic diffuser. The ozone concentration in the feed gas was $32 \mathrm{mg} \mathrm{dm}^{-3}$, which was measured at $254 \mathrm{~nm}$ with a UV spectrophotometer (WPA Lightwave S2000, UK); the contact time was 30 or $60 \mathrm{~min}$, and the flow rate of the bubbling gas was $1 \mathrm{dm}^{3} \min ^{-1}$. 
The microwave treatment was performed in a Labotron 500 professional microwave equipment (Buchner-Guyer AG, Switzerland), at $250 \mathrm{~W}$ microwave power and at 2.45 $\mathrm{GHz}$ frequency. The turntable of the microwave equipment and a modus stirrer compensated for the non-uniform heat distribution. For the measurements, $200 \mathrm{~g}$ of sludge sample was diluted with $200 \mathrm{ml}$ distilled water in a PTFE vessel, and then irradiated for 5 or $10 \mathrm{~min}$. For acidic and microwave pretreatment, the $\mathrm{pH}$ was adjusted to $\mathrm{pH} 2$ with $1 \mathrm{M} \mathrm{HCl}$.

Biogas production tests were performed in triplicate in batch mode under mesophilic conditions, at $30{ }^{\circ} \mathrm{C}$ for 30 days, in an anaerobic laboratory digester with a pressure measuring head (Oxitop Control AN12 measurement system, WTW Gmbh, Germany). The capacity of digesters was $1000 \mathrm{~mL}$, the volume of diluted sample was $200 \mathrm{~mL}$, the dry content of sludge was adjusted to $6 \%$ with sterile water, considering the pressure range of equipment. The pressure values were automatically stored by barometrical heads in every 2 hours. The digester was inoculated with acclimated sludge from a municipal wastewater treatment plant (Hódmezővásárhely, Hungary) in order to eliminate the possible lag-phase of anaerobic biological degradation process. After inoculation nitrogen gas was flowed through the reactor to prevent exposure to air. The $\mathrm{pH}$ was adjusted to $\mathrm{pH} 7.2$ with $1 \mathrm{M} \mathrm{NaOH}$ and $1 \mathrm{M} \mathrm{HCl}$ solution.

For simple methane determination, measurements were performed in parallel in two vessels: one of them contained a $\mathrm{CO}_{2}$ absorber, while the other measured the total gas pressure. The resulting pressure difference was proportional to the $\mathrm{CO}_{2}$ concentration, and the remaining overpressure was proportional to the methane concentration. In addition the accurate composition of the biogas produces was measured by gas chromatographic and mass spectrometric method (Agilent 6890N-5976 GC-MS). In the case of methane content, there was a close correlation between the pressure difference method and gas chromatographic determination $(\mathrm{R}>0.85)$.
The net energy product (NEP) of processes involving with microwave pretreatment can be calculated via Equation [2]

$$
N E P=q_{\text {comb }} \times m_{\text {methane }}-P_{m} \times \tau
$$

where NEP is the net energy product [J], $\mathrm{q}_{\text {comb }}$ is the combustion heat $\left[\mathrm{J} \mathrm{kg}^{-1}\right]$ of methane, $\mathrm{m}_{\text {methane }}$ the mass of the methane produced $[\mathrm{kg}], \mathrm{P}_{\mathrm{m}}$ the power of the microwave magnetron [W], and $\tau$ is the duration of treatment [s].

For the examination of preozonation treatment, the same equation was applied except that the magnetron power was replaced by the power of ozone generator.

\section{RESULTS AND DISCUSSION}

In the first series of experiments the effect of different pretreatment on the value of COD and BOD was investigated (Figure $1 \mathrm{a}, 1 \mathrm{~b}$ ).

It was found that the ozone treatment and the combined ozone/microwave treatment decreased COD, while BOD increased. After the 30-min ozone pretreatment, the microwave irradiation caused approximately the same COD decrease as that resulting from the 60-min ozone treatment. There was no significant difference between the COD values of ozone- and microwave-treated samples, but the combined ozone/microwave and acidic microwave treatment was a less time-consuming process.

The ozone, microwave and combined treatments increased the biodegradability because COD was decreased in parallel with increasing BOD.

The 30-min ozone pretreatment enhanced the biodegradability about 3 -fold, from $24 \%$ to $62 \%$. Repeated $30 \mathrm{~min}$ ozone treatment enhanced the biodegradability up to $90 \%$. The combination of microwave and ozone treatment increased the biodegradability up to close to $100 \%$ (Figure 2).

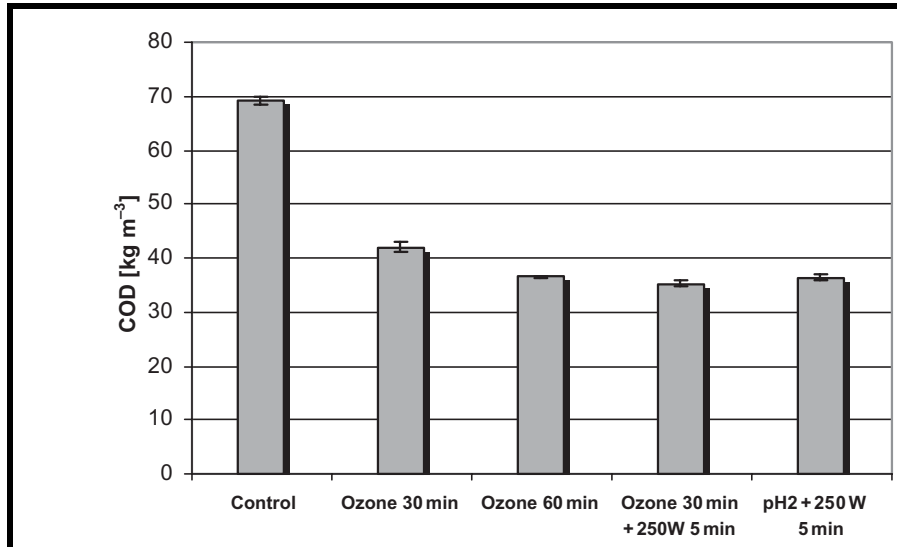

(a)

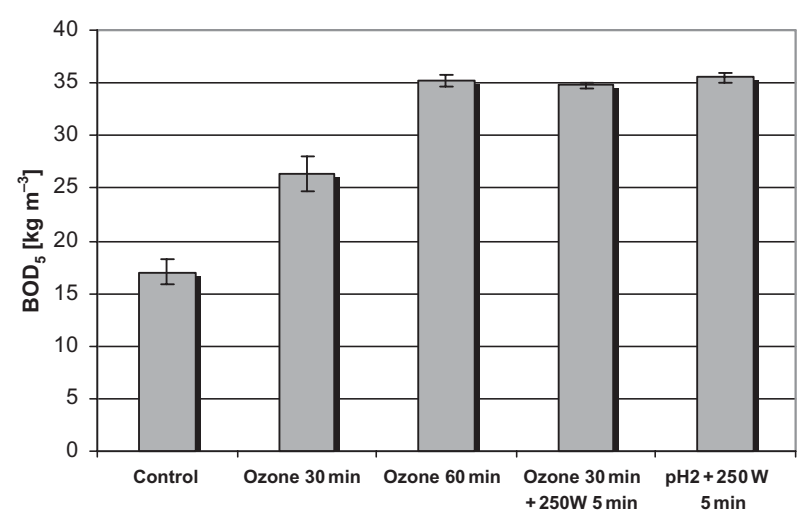

(b)

FIGURE 1. Changes in $\mathrm{COD}(\mathrm{a})$ and $\mathrm{BOD}_{5}(\mathrm{~b})$ of diluted sludge solutions due to various treatments. 


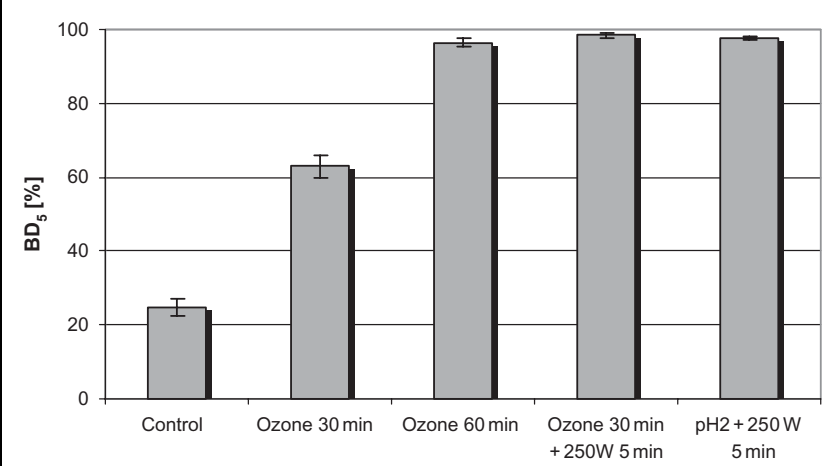

FIGURE 2. Changes in biodegradability due to ozone treatment and ozone/microwave treatment.

In the next series of experiments the biogas production was measured. Gas chromatographic and mass spectrometric measurements showed that after 30 days the fermenter contains gaseous $\mathrm{CO}_{2}$ and $\mathrm{CH}_{4}$. The non-pre-treated sludge was used as control sample. By our preliminary measurements the microwave treatments alone did not have significant effect on the biogas production, whereas the ozone and combined ozone/microwave and acidic microwave treatments enhanced it (Figure 3).
The results revealed that all types of pretreatments enhanced the methane-production relatively to the less degradable control (18.0 $\mathrm{mL} \mathrm{g}^{-1}$ dry matter). There was no significant difference between the biogas production of the $30 \mathrm{~min}$, the $60 \mathrm{~min}$ and the combined ozone/ microwave pretreatments. But the stronger ozonation decreased the COD and therefore the specific methane product $\left(\mathrm{mL} \mathrm{g}^{-1} \mathrm{COD}\right)$ increased. The microwave irradiation at $\mathrm{pH} 2$ resulted in significantly higher methane production comparing to ozonation, which could be explained by bigger efficiency in solubilization of chemicals and by the thermal effect of sludge treatment (Bougrier et al., 2006). The combined acidic and microwave treatment could significant accelerate the hydrolysis of organic matter, which is the limiting step of the microbial degradation (Li and Noike, 1992) (Table 1).

The initial specific biogas production rate $\left(\mathrm{dm}^{3} \mathrm{~kg}^{-1} \mathrm{day}^{-1}\right)$ was calculated as the slope of the straight line fitting the amount of biogas produced during the initial 10 days of the test (Climent et al., 2007).

The results demonstrate that all treatments enhanced the initial specific biogas production rate. When combined ozone/microwave treatment was applied, the increment was 10 -fold, however, the acidic microwave treatment enhanced the initial biogas production rate as high as $25-$

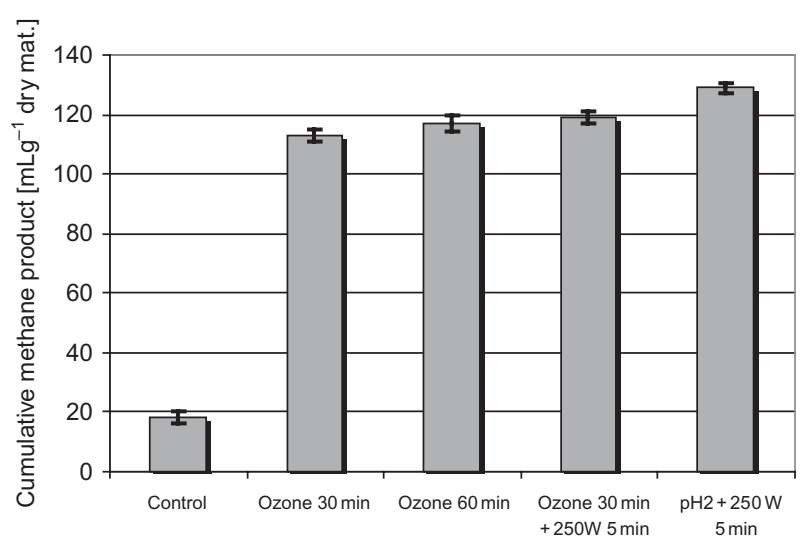

(a)

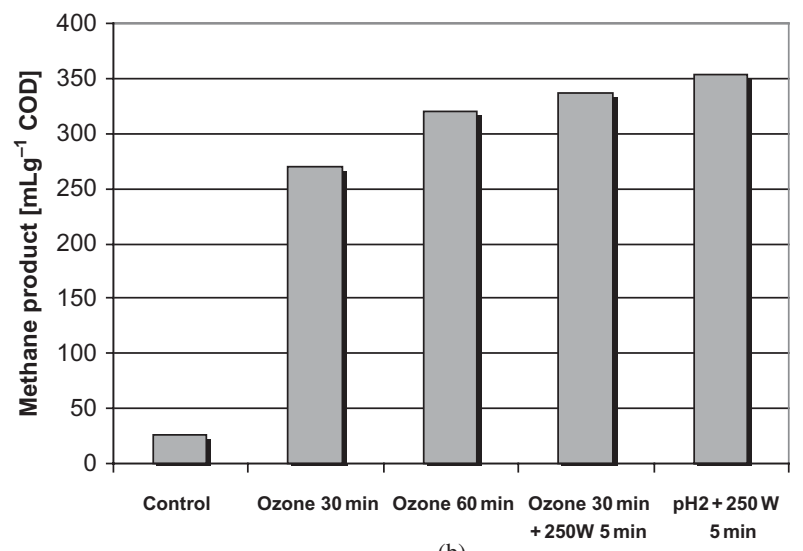

(b)

FIGURE 3. The cumulative methane product of pretreated and control sample (a-mL g ${ }^{-1}$ dry matter, b-mL g ${ }^{-1} \mathrm{COD}$ unit).

TABLE 1. The Parameters of Biodegradability After Different Pre-treatments

\begin{tabular}{lccc}
\hline Pretreatment & $\begin{array}{c}\text { Treatment } \\
\text { time }[\mathrm{min}]\end{array}$ & $\begin{array}{c}\mathrm{BD}_{5} \% \\
\left(\mathrm{BOD}_{5} / \mathrm{COD}\right) \times 100\end{array}$ & $\begin{array}{c}\text { Initial biogas } \\
\text { production } \\
\text { rate }\left[\mathrm{cm}^{3} \mathrm{~g}^{-1} \mathrm{day}^{-1}\right]\end{array}$ \\
\hline Untreated & - & 26 & 1.037 \\
Ozone & 30 & 63 & 3.77 \\
Ozone & 60 & 94 & 7.40 \\
Ozone $/$ microwave & $30+5$ & 96 & 9.52 \\
Microwave $(\mathrm{pH}=2)$ & 5 & 95 & 25.75 \\
\hline
\end{tabular}


fold. There was a considerable difference between the change of the biodegradability-determined via aerobic microorganisms - and methane or biogas product, which was measured by anaerobic microorganisms in the case of 30-min ozone pretreatment comparing with control and other pretreatments. The 30-min ozone treatment caused an oxidizing effect, but aerobic microorganisms during 5 days were not able to degrade organic matter to the same extent as anaerobic bacteria during 30 days. For this reason a considerable difference was experienced in the efficiency of aerobic degradation (biodegradability) and anaerobic degradation (methane product).

The positive effect of common microwave and ozone pretreatments could be explained by changing of the soluble organic matter content, because the aerobic biodegradability and anaerobic digestible were linked to it (Bougrier et al., 2007; Eskicioglu et al., 2007). In consequence of high quantity but recalcitrant organic matter content of canned maize production sludge the increasing of biodegradable organic substances enhanced the biogas production on a large scale. With lengthy anaerobic digestion, the ozone pre-treatment caused not only higher cumulative biogas production but shorter lagphase of anaerobic decomposition.

As concerns calculating energy balance of the treatments, the results showed that the 30-min ozone treatment and the 5-min microwave treatment at $\mathrm{pH} 2$ were associated with an energy increase, while 60-min ozone treatment and the combined ozone/microwave treatment needed more energy than obtained from methane production (Figure 4).

Accordingly, taking everything into account i.e., biodegradability, the biogas production, and energetic aspect, the 30-min ozone pretreatment and the microwave pretreatment at $\mathrm{pH} 2$ were more cost effective.

\section{CONCLUSION}

The results show that the microwave treatment of acidic sludge solution resulted in higher biodegradability and enhanced biogas production as well. The ozone pretreatment and the combined ozone/microwave treatment also increased the biodegradability and methane production

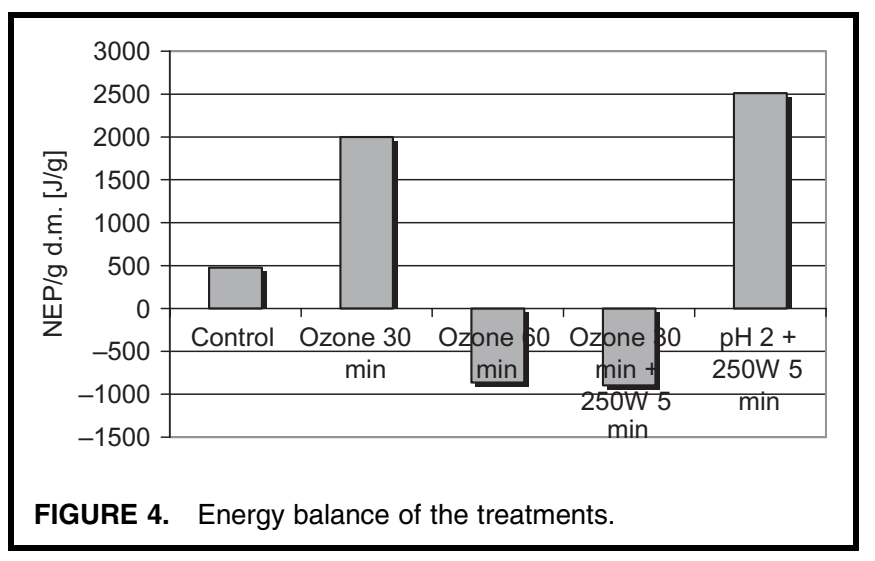

compared to the original, non-treated sludge. However, when the processing time is also taken into consideration, the energetic benefits of the pretreatments are not so unambiguous, only the short-time ozone or microwave treatment resulted in net energy production. These experiments indicate that the ozone pretreatment is appropriate for decreasing the organic content of canning sludge, making the organic component of the sludge more accessible for anaerobic degradation and thereby increasing biogas production.

\section{ACKNOWLEDGMENTS}

This work was supported by the Hungarian National Office of Research and Technology (NKTH) and the Agency for Research Fund Management and Research Exploitation (KPI) under contract No. RET-07/2005 and GVOP 3.2.1.2004-04. 0252/3.0 project.

\section{REFERENCES}

Bougrier, C., A. Battimelli, J.P. Delgenes, and H. Carrere, "Combined Ozone Pretreatment and Anaerobic Digestion for the Reduction of Biological Sludge Production in Wastewater Treatment", Ozone Sci. Eng., 29(3):201-206 (2007).

Climent, M., I. Ferrer, M. del Mar Baeza, A. Artola, F. Vázquez, and X. Fonta, "Effects of Thermal and Mechanical Pretreatments of Secondary Sludge on Biogas Production under Thermophilic Conditions", Chem. Eng. J., 133(1-3):335-342 (2007).

Déléris, S., E. Paul, J.M. Audic, M. Roustan, and H. Debellefontaine, "Effect of Ozonation on Activated Sludge Solubulization and Mineralization", Ozone Sci. Eng., 22(5):473-486 (2000).

Eskicioglu, C., K. J. Kennedy, and R. L. Droste, "Characterization of Soluble Organic Matter of Waste Activated Sludge Before and After Thermal Pretreatment", Water Res., 40: 3725-3736 (2006).

Eskicioglu, C., N. Terzian K. J. Kennedy, R. L. Droste, and M. Hamoda, "Athermal Microwave Effects for Enhancing Digestibility of Waste Activated Sludge", Water Res., 41:2457-2466 (2007).

Gavala, H. N., U. Yenal, I. V. Skiadas, P. Westerman and B. K. Ahring, "Mesophilic and Thermophilic Anaerobic Digestion of Primary and Secondary Sludge", Effect of Pre-treatment at Elevated Temperature", Water Res., 37:5461-4572 (2003).

Hyung, H., S. Lee and J. Yoon, "Effect of Preozonation of Flux and Water Quality in Ozonation and Ultrafiltration Hybrid System for Water Treatment", Ozone Sci. Eng., 22:637 (2000).

Kim, J., C. Park, T. H. Kim, M. Lee, S. Kim, S. W. Kim, and J. Lee, "Effects of Various Pretreatments for Enhanced Anaerobic Digestion with Waste Activated Sludge", J. Biosci. Bioeng., 95:271-275 (2003).

Li, Y. Y. and T. Noike. "Upgrading of Anaerobic Digestion of Waste Activated Sludge by Thermal Pretreatment", Water Sci. Technol., 26(3-4):857-866 (1992).

Neyens, E. and J. Baeyens, "A Review of Thermal Sludge Pre-treatment Processes to Improve Dewaterability”, J. Hazard. Mater., B98:51-67 (2003).

Neyens, E., J. Baeyens, R. Dewil, and B. DeHeyder, "Advanced Sludge Treatment Affects Extracellular Polymeric Substances to Improve Activated Sludge Dewatering”, J. Hazard. Mater., 106B:83-92 (2004).

Watenabe, H., T. Kitamure, S. Ochi, S. Ortega, and M. Ozaki, "Inactivation of Pathogenetic Bacteria under Mesophilic and Thermophilic Conditions", Water Sci. Technol., 36(6-7):239-246 (1997).

Weemaes, M., H. Grootaerd, F. Simoens, and W. Verstraete, "Anaerobic Digestion of Ozonized Biosolids", Water Res. 34(8):2330-2336 (2000). 
Copyright of Ozone: Science \& Engineering is the property of Taylor \& Francis Ltd and its content may not be copied or emailed to multiple sites or posted to a listserv without the copyright holder's express written permission. However, users may print, download, or email articles for individual use. 